\title{
Certified cause of death in children and young adults with cerebral palsy
}

\author{
P M Evans, E Alberman
}

\begin{abstract}
The status of 732 children suffering from cerebral palsy from the South East Thames region (births from 1970-9) was ascertained at the end of 1989, and copies of death certificates of the 73 children who have died, aged 4 weeks to nearly 16 years, were obtained. Infantile cerebral palsy (ICD Code 343-) was coded as the underlying cause of death in only $16(22 \%)$ cases. On $28(38 \%)$ certificates there was no mention of any form of cerebral palsy, the proportion in which it was not mentioned increasing with age. In $20(28 \%)$ cases the coded underlying cause of death was respiratory, hence in published national statistics the number of deaths from respiratory causes is inflated. A postmortem examination was known to have been performed in 23 cases, but the recorded information was in some cases limited to a 'terminal event'. The importance of good data on the death certificate, and the significance of published national statistics, need to be communicated to all those involved in the certification process if cerebral palsy and other chronic conditions, which raise the relative risk of death, are not to be under-represented.
\end{abstract}

The under-representation of chronic 'non-fatal' diseases in mortality statistics has been documented. ${ }^{2}$ The life expectancy, the cause of death, and its antecedent causes in individuals suffering from cerebral palsy are of interest to those seeking to ensure that their long term needs are provided for. If cerebral palsy is similarly under-represented, however, published national statistics based upon death certificate data might lead to misleading conclusions.

The South East Thames region cerebral palsy register (births from 1970-9) has provided the cases for a population based view of survival of those suffering from the various types of cerebral palsy with different degrees of impairment. This paper presents the data obtained from death certificate copies relating to 73 children who have died.

Department of Clinical Epidemiology, The London Hospital Medical College, Turner Street,

London E1 2AD

P M Evans

E Alberman

Correspondence to:

Dr Evans.

Accepted 10 September 1990 (births from 1970-9) was assembled between 1978 and 1981 using multiple sources of ascertainment. A more detailed description of the methodology of this study may be found elsewhere. $^{3}$ A total of 732 cases, of whom 420 were male and 312 were female, were traced again in 1988, mainly through the National Health Service Central Register (NHSCR) at Southport. By the end of 1989, 73 children (47 boys and 26 girls) were known to have died, at ages ranging from 4 weeks to $15 \cdot 8$ years. Survival analysis is published elsewhere. ${ }^{4}$

Copies of the death certificates have been received from NHSCR for the 73 cases who have died. These show the certified cause of death and any causes antecedent to it in part I of the certificate, contributory cause(s) in part II, and the coded underlying cause of death using the International Classification of Disease (ICD) 9th revision which is selected according to international coding procedures.

\section{Results}

Table 1 provides a full description of the cause of death information on the death certificates, plus the type of cerebral palsy as given to us by each child's paediatrician, and our explanatory comments where appropriate. In a number of cases minor spelling corrections have been made, but otherwise the data are recorded exactly as given to us, and include some obvious errors.

CEREBRAL PALSY ON DEATH CERTIFICATES

Except for deaths occurring in the years 1985 and 1986, when the Office of Population, Censuses and Surveys (OPCS) carried out multiple cause coding, only underlying cause of death is coded. The proportion of cases in whom some form of cerebral palsy appears somewhere on the death certificate declines with age, but the proportion in whom the underlying cause is coded as 343- follows a different pattern (see table 2).

The presentation of these figures is complicated by two factors: firstly, three cases (314, 540 , and 740), all of whom died at ages less than 7 years (the diagnoses on the death certificate being spastic diplegia, spastic quadriplegia, and quadriparesis,) were allocated the underlying cause code 344- (other paralytic syndromes) for reasons that are not apparent to us; these cases are classed as having a mention of cerebral palsy on the death certificate. Secondly, two cases (964 and 965) who died aged 4 and 5 weeks were ascertained by means of a search by OPCS using underlying cause coding, but the cause was given as 'cerebral birth anoxia'; these two cases have been counted as having a mention of cerebral palsy in order to avoid confusion. 
Table 1 Survival. Certified cause of death and clinical diagnosis (73 cases)

\begin{tabular}{|c|c|c|c|c|c|c|c|c|}
\hline \multirow{2}{*}{$\begin{array}{l}\text { Case } \\
\text { No }\end{array}$} & \multirow[t]{2}{*}{ Alive } & \multicolumn{4}{|l|}{ Death certificate information } & \multirow{2}{*}{$\begin{array}{l}I C D \\
\text { code }\end{array}$} & \multirow{2}{*}{$\begin{array}{l}\text { Diagnosis given to us } \\
\text { by paediatrician }\end{array}$} & \multirow[t]{2}{*}{ Comment } \\
\hline & & $1 a$ & lb & Ic & II & & & \\
\hline 025 & $10 \cdot 70-08.79$ & $\begin{array}{l}\text { Acute lymphoblastic } \\
\text { leukaemia }\end{array}$ & - & - & $\begin{array}{l}\text { Epilepsy, spastic quadriplegia, } \\
\text { severely subnormal }\end{array}$ & 2040 & Spastic quadriplegia & \\
\hline 041 & $07 \cdot 71-04 \cdot 72$ & Bronchopneumonia & - & - & Microcephaly, severe subnormality & $485 \mathrm{X}$ & Cerebral palsy & \\
\hline 042 & $04 \cdot 73-10 \cdot 88$ & Cerebral failure & Microcephaly, epilepsy & $\begin{array}{l}\text { Severe physical and mental } \\
\text { subnormality }\end{array}$ & - & 3181 & Spastic quadriplegia & \\
\hline 075 & $08 \cdot 77-05 \cdot 83$ & Bronchopneumonia & Mental retardation & - & - & $319 \mathrm{X}$ & Spastic quadriplegia & \\
\hline 076 & $09 \cdot 71-05.86$ & Aspiration pneumonia & Cerebral palsy & - & - & 3439 & Spastic quadriplegia & \\
\hline 085 & $11 \cdot 73-11 \cdot 85$ & Bronchopneumonia & Quadriplegia & Previous meningitis & - & 3229 & Spastic & \\
\hline 119 & $11 \cdot 76-04 \cdot 85$ & Respiratory infection & Chronic obstructive airway disease & - & $\begin{array}{l}\text { Microcephaly, epilepsy, and spastic } \\
\text { quadriplegia }\end{array}$ & $496 \mathrm{X}$ & Spastic quadriplegia & \\
\hline 140 & $08 \cdot 71-12 \cdot 78$ & Bronchopneumonia & - & - & Cerebral palsy & $485 \mathrm{X}$ & Dystonic spastic quadriplegia & \\
\hline 146 & $08 \cdot 75-04 \cdot 84$ & Chickenpox & - & - & Lissencephaly & $052 \mathrm{X}$ & Double hemiplegia & \\
\hline 147 & $08 \cdot 70-03 \cdot 75$ & Bronchopneumonia & - & - & Hydrocephalus_cerebral hypoplasia & $485 \mathrm{x}$ & Cerebral palsy & \\
\hline 148 & $07 \cdot 78-05 \cdot 82$ & $\begin{array}{l}\text { Overwhelming measles } \\
\text { infection }\end{array}$ & - & - & $\begin{array}{l}\text { Spastic quadriplegia and mental } \\
\text { retardation }\end{array}$ & 0559 & Cerebral palsy & \\
\hline 169 & $02 \cdot 74-01 \cdot 81$ & Hypoxia & Chronic bronchitis & - & Severe subnormality & 4919 & Spastic quadriplegia & \\
\hline 191 & $10 \cdot 71-11 \cdot 80$ & Bronchopneumonia & - & - & Cerebral palsy, birth asphyxia & $485 \mathrm{X}$ & Spastic quadriplegia & \\
\hline 195 & $05 \cdot 73-04 \cdot 83$ & Cardiac arrest & Hypotonic cerebral palsy & - & Severely subnormal & 3439 & Athetoid & \\
\hline 205 & $12 \cdot 72-02 \cdot 81$ & Acute bronchitis & Acute bronchitis & - & Cerebral palsy & 4660 & Athetoid & \\
\hline 211 & $01 \cdot 74-01 \cdot 76$ & Bilateral bronchopneumonia & Spasticity, mental retardation & - & Epilepsy & $319 \mathrm{X}$ & Spastic quadriplegia & \\
\hline 215 & $06 \cdot 70-04 \cdot 75$ & Bronchopneumonia & - & - & Microcephaly & $485 \mathrm{X}$ & Spastic quadriplegia & \\
\hline 239 & $10 \cdot 73-01 \cdot 78$ & Grand mal epilepsy & Cerebral palsy & - & Acute upper respiratory infection & 3439 & Ataxia-mixed & \\
\hline 245 & $02 \cdot 70-10 \cdot 76$ & Bronchopneumonia & - & - & Cerebral palsy & $485-$ & Spastic quadriplegia & \\
\hline 247 & $12 \cdot 72-06 \cdot 79$ & Pneumonia & - & - & Cerebral palsy, neonatal meningitis & 486- & Spastic quadriplegia & \\
\hline 258 & $09.71-01.86$ & Lobar pneumonia & - & - & - & 481- & Spastic quadriplegia & \\
\hline 264 & $12 \cdot 70-01 \cdot 76$ & Bronchopneumonia & Primary cerebral degeneration & - & - & 3319 & Dystonic spastic & \\
\hline 267 & $05 \cdot 77-12 \cdot 79$ & $\begin{array}{l}\text { Haemolytic streptococcal } \\
\text { pneumonia }\end{array}$ & - & - & Spastic diplegia & 4823 & Severe quadriplegia & \\
\hline 287 & $08 \cdot 71-01 \cdot 75$ & Chest infection & Severe mixed cerebral palsy & - & - & 3439 & Dystonic mixed type & \\
\hline 292 & $02 \cdot 79-01 \cdot 82$ & Stevens-Johnson syndrome & - & - & Choreoathetoid cerebral palsy & 6951 & Choroathetoid & \\
\hline 293 & $01 \cdot 71-08 \cdot 84$ & $\begin{array}{l}\text { A1: Primary alveolar } \\
\text { hypoventilation syndrome }\end{array}$ & A2: Microcephaly (small brain) & - & - & 7421 & Spastic quadriplegia & \\
\hline 306 & $10 \cdot 73-10 \cdot 78$ & Pneumonia & Pneumonary dysplasix & Cerebral palsy & - & 7485 & Dystonic quadriplegia & \\
\hline 307 & $04 \cdot 73-02 \cdot 78$ & Bronchopneumonia & Spastic quadriplegia & Microcephaly & - & 7421 & Spastic quadriplegia & \\
\hline 314 & $01 \cdot 74-04 \cdot 77$ & Chronic renal failure & Renal tubular acidosis & $\begin{array}{l}\text { Spastic diplegia, severe meckel } \\
\text { retardation, microcephaly }\end{array}$ & $1-$ & 3442 & Spastic quadriplegia & $\begin{array}{l}\text { 'Meckel' counted as } \\
\text { 'mental' in } \\
\text { calculations }\end{array}$ \\
\hline 352 & $02 \cdot 70-01 \cdot 71$ & Gastroenteritis & Bronchopneumonia & - & Cerebral palsy, mental retardation & 0558 & Athetoid & \\
\hline 353 & $08 \cdot 76-07 \cdot 87$ & Epilepsy & Congenital hydrocephalus & - & - & 7423 & Spastic quadriplegia & \\
\hline 370 & $07 \cdot 76-08 \cdot 83$ & Bronchopneumonia & Epilepsy & Cerebral atrophy & - & $7428,485,3459$ & Athetoid & $\begin{array}{l}\text { [Scottish death } \\
\text { certificate] }\end{array}$ \\
\hline 371 & $02 \cdot 74-05 \cdot 75$ & Resp failure & Pneumonia & - & $\begin{array}{l}\text { Gross psychomotor delay, secondary } \\
\text { epilepsy }\end{array}$ & $486 \mathrm{X}$ & Spastic left>right & \\
\hline 378 & $03.74-03.78$ & Al: Cardiorespiratory failure & $\begin{array}{l}\text { A2: Congenital cerebral palsy } \\
\text { ('spasticity') }\end{array}$ & A3: Epilepsy & - & 3459 & Spastic quadriplegia & \\
\hline 384 & $07 \cdot 72-06 \cdot 73$ & $\begin{array}{l}\text { Inhalation of vomit in } \\
\text { association with } \\
\text { neuromuscular disease }\end{array}$ & - & - & - & 3589 & Hypotonic athetoid & \\
\hline 387 & $09 \cdot 72-05 \cdot 74$ & Bronchopneumonia & Cerebral palsy & - & - & $343 X$ & $\begin{array}{l}\text { Severe asymmetrical dystonic } \\
\text { quadriplegia }\end{array}$ & \\
\hline 392 & $07 \cdot 70-12 \cdot 85$ & Reye's syndrome & - & - & - & 3318 & Cerebral palsy & \\
\hline 396 & $01 \cdot 76-09 \cdot 81$ & $\begin{array}{l}\text { Multiple injuries } \\
\text { (accidental death) }\end{array}$ & - & - & - & E9289, 9598 & Crural monoplegia & Inquest held \\
\hline 431 & $09 \cdot 73-12 \cdot 81$ & Status epilepticus & Hydrocephalus and cerebral palsy & Neonatal meningitis & - & 3229 & Spastic quadriplegia + ataxia & \\
\hline 439 & $12 \cdot 73-07 \cdot 86$ & Bronchopneumonia & - & - & - & 485- & Dystonic quadriplegia + athetosis & \\
\hline 478 & $03 \cdot 70-01 \cdot 79$ & Viral pneumonitis & - & - & - & 4809 & [No diagnosis received] & $\begin{array}{l}\text { [Notified as } \\
\text { cerebral palsy] }\end{array}$ \\
\hline 504 & $09 \cdot 70-03.86$ & Aspiration of vomitus & Cerebral palsy & Hydrocephalus & - & 3439 & Spastic quadriplegia & \\
\hline 508 & $05 \cdot 70-10 \cdot 80$ & Adrenal failure due to & $\begin{array}{l}\text { Adrenal hypoplasia and } \\
\text { bronchopneumonia }\end{array}$ & - & Hydrocephalus & 7591 & Cerebral palsy & \\
\hline 525 & $06.77-07.88$ & Status epilepticus & Spastic quadriplegia (from birth) & - & $\begin{array}{l}\text { Bronchopneumonia, hiatus hernia with } \\
\text { iron deficiency anaemia }\end{array}$ & 3432 & Spastic quadriplegia & \\
\hline 533 & $08 \cdot 71-12 \cdot 74$ & Bronchopneumonia & Congenital heart disease & Mental retardation & - & 7469 & Athetoid+ataxic & \\
\hline 540 & $03 \cdot 78-04 \cdot 84$ & Respiratory insufficiency & - & - & $\begin{array}{l}\text { Spastic quadriplegia and severe } \\
\text { mental retardation }\end{array}$ & 3440 & Spastic quadriplegia & \\
\hline 563 & $01 \cdot 78-01 \cdot 80$ & Bronchopneumonia & - & - & Cerebral palsy & $485 \mathrm{X}$ & Spastic quadriplegia & \\
\hline 575 & $12 \cdot 77-12 \cdot 86$ & Gastrointestinal haemorrhage & $=-$ & - & Chest infection, spastic quadriplegia & 5789 & Spastic quadriplegia & \\
\hline 596 & $03 \cdot 73-04 \cdot 81$ & $\begin{array}{l}\text { Ependymoma of fourth } \\
\text { ventricle }\end{array}$ & - & - & - & 1915 & Spastic quadriplegia & \\
\hline 614 & $06 \cdot 71-03 \cdot 82$ & Hypostatic pneumonia & Congenital hydrocephalus & - 1 & - & 7423 & Spastic quadriplegia & \\
\hline 632 & $10 \cdot 70-11 \cdot 78$ & Bronchopneumonia & Gastroenteritis & $\begin{array}{l}\text { Severe mental handicap due to- } \\
\text { neonatal meningitis }\end{array}$ & - & 3229 & Spastic quadriplegia + athetoid & \\
\hline 659 & $04 \cdot 79-06 \cdot 80$ & Acute bronchiolitis & - & - & - & 4661 & Spastic quadriplegia & \\
\hline 661 & $04 \cdot 78-11 \cdot 80$ & Encephalitis & - & - & Cerebral palsy & 3239 & Spastic quadriplegia & \\
\hline 686 & $06 \cdot 72-10 \cdot 73$ & $\begin{array}{l}\text { Severe hypostatic } \\
\text { bronchopneumonia }\end{array}$ & Septicaemia & - & - & 0389 & [No diagnosis received] & $\begin{array}{l}\text { [Notified as } \\
\text { cerebral palsy] }\end{array}$ \\
\hline 726 & $06 \cdot 72-01 \cdot 77$ & Bronchopneumonia & - & - & Cerebral palsy & 485- & Cerebral palsy & \\
\hline 727 & $10 \cdot 70-02 \cdot 71$ & Congestive cardiac failure & Bronchopneumonia & - & Cerebral palsy & $485 x$ & Quadriplegia & \\
\hline 728 & $03 \cdot 76-08 \cdot 77$ & Epilepsy & Cerebral palsy & Microcephaly & - & 7421 & Cerebral palsy & \\
\hline 729 & $07 \cdot 74-09 \cdot 78$ & Bronchopneumonia & Whooping cough & - & $\begin{array}{l}\text { Microcephalic spastic quadriplegia, } \\
\text { mental retardation }\end{array}$ & 0339 & Spastic quadriplegia & \\
\hline 730 & $01 \cdot 72-08 \cdot 72$ & Bronchopneumonia & Cerebral palsy & Cerebral atrophy & - & 3319 & Cerebral palsy & \\
\hline 732 & $12 \cdot 77-12 \cdot 87$ & Asphyxia & Cerebral atrophy & - & - & 3319 & [No diagnosis received] & $\begin{array}{l}\text { [Notified as } \\
\text { cerebral palsy] }\end{array}$ \\
\hline 740 & $01 \cdot 79-06 \cdot 80$ & Cardiac arrest & Chest infection & Quadriparesis & Congenital infection & 3440 & Spastic quadriplegia & \\
\hline 742 & $09 \cdot 74-06.80$ & Hypostatic pneumonia & Cerebral palsy & - & - & 3439 & Severely hypotonic & \\
\hline 905 & $12 \cdot 71-10 \cdot 87$ & Cardiorespiratory failure & Spastic quadriplegia & Cerebral palsy & - & 3439 & Spastic quadriplegia & \\
\hline 923 & $03 \cdot 75-12 \cdot 76$ & Meningitis (Staphy albus) & $\begin{array}{l}\text { Chronic infection in a child with } \\
\text { spina bifida and hydrocephalus }\end{array}$ & - & - & 7410 & $\begin{array}{l}\text { Hydrocephalus, spina bifida, } \\
\text { right hemiplegia }\end{array}$ & [Dubious case] \\
\hline 943 & $10 \cdot 79-12 \cdot 79$ & Bronchopneumonia & Porencephaly & - & - & 7424 & Porencephaly & $\begin{array}{l}\text { [Notified as } \\
\text { cerebral palsy] }\end{array}$ \\
\hline 959 & $12 \cdot 70-11 \cdot 71$ & Bronchopneumonia & - & - & Cerebral palsy & $485 \mathrm{X}$ & Cerebral palsy & \\
\hline 960 & $12 \cdot 71-04 \cdot 73$ & $\begin{array}{l}\text { Inhalation of stomach } \\
\text { contents due to cerebral } \\
\text { palsy }\end{array}$ & - & - & - & $343 \mathrm{X}$ & Cerebral palsy & \\
\hline 961 & $01 \cdot 70-10 \cdot 71$ & Respiratory arrest & Spastic CP & Septicremia & - & $343 X$ & Spastic & \\
\hline 962 & $10 \cdot 70-03 \cdot 72$ & Bronchopneumonia & Internal hydrocephalus & Cerebral palsy & - & $343 \mathrm{X}$ & [OPCS dead case] & \\
\hline 963 & $01 \cdot 70-01 \cdot 73$ & Bronchopneumonia & Cerebral palsy & - & - & $343 \mathrm{X}$ & [OPCS dead case] & \\
\hline 964 & $02 \cdot 74-03 \cdot 74$ & Bronchopneumonia & Epilepsy & Cerebral birth anoxia & - & $343 \mathrm{X}$ & [OPCS dead case] & \\
\hline 965 & $04 \cdot 74-05 \cdot 74$ & $\begin{array}{l}\text { (Bronchopneumonia) } \\
\text { Status epilepticus }\end{array}$ & $\begin{array}{l}\text { Irreversible cerebral anoxia } \\
\text { at birth }\end{array}$ & - & - & $343 x$ & [OPCS dead case] & $\begin{array}{l}()=\text { cause on death } \\
\text { certificate which } \\
\text { was revised }\end{array}$ \\
\hline 966 & $04 \cdot 74-07 \cdot 74$ & $\begin{array}{l}\text { (Pneumonia) Acute } \\
\text { respiratory failure }\end{array}$ & - & Cerebral palsy & (Cerebral palsy) & $343 X$ & [OPCS dead case] & $\begin{array}{l}()=\text { cause on death } \\
\text { certificate which } \\
\text { was revised }\end{array}$ \\
\hline
\end{tabular}


Table 2 Cerebral palsy on the death certificate

\begin{tabular}{lccc}
\hline $\begin{array}{l}\text { Age at } \\
\text { death } \\
\text { (years) }\end{array}$ & $\begin{array}{l}\text { No of } \\
\text { cases }\end{array}$ & $\begin{array}{l}\text { No (\%) with } \\
\text { cerebral palsy } \\
\text { (343-) as } \\
\text { underlying } \\
\text { cause }\end{array}$ & $\begin{array}{l}\text { No (\%) with } \\
\text { mention of } \\
\text { cerebral palsy } \\
\text { on death } \\
\text { certificate* }\end{array}$ \\
\hline$<1$ & 9 & $3(33)$ & $7(78)$ \\
$1-<4$ & 21 & $6(29)$ & $15(71)$ \\
$4-<7$ & 16 & $2(13)$ & $10(63)$ \\
$7-<10$ & 13 & 0 & $7(54)$ \\
$10-<13$ & 7 & $2(29)$ & $3(43)$ \\
$13-16 \dagger$ & 7 & $3(43)$ & $3(43)$ \\
\hline Total & 73 & $16(22)$ & $45(62)$
\end{tabular}

*Includes three cases where underlying cause is coded 344-; also two cases where the cause was given as 'cerebral birth anoxia' that were coded 343-. The trend is significant $(p=0.04)$.

tThe highest age at death was 15.8 years.

OTHER CEREBRAL CONDITIONS

Of the $\mathbf{4 5}$ cases with a mention of some form of cerebral palsy on the death certificate, 12 also had another mention of a cerebral condition other than mental subnormality or epilepsy; of the 28 cases with no mention of cerebral palsy, 16 mentioned another cerebral condition; in 12 cases neither cerebral palsy nor any other cerebral condition was mentioned. Among the 'other cerebral' conditions were microcephaly (nine cases-of which five also mentioned cerebral palsy), hydrocephaly (eight cases-of which three also mentioned cerebral palsy), and cerebral atrophy (three cases_ of which two also mentioned cerebral palsy).

Also included in this group are three cases in whom previous meningitis was mentioned (85, 247 , and 632). In another child (923), with spina bifida and hydrocephalus, meningitis (described as a chronic infection) was by implication present at the time of death. In another case (661) encephalitis was given as the cause without any indication as to timing, although as it was not mentioned in the information originally supplied to use by the child's paediatrician we assume that this was a late event. In one case (632) the coding failed to reflect the chronology of the condition as recorded on the death certificate. A child who died at 8 years of age was certified as follows: la: bronchopneumonia, lb: gastroenteritis, 1c: severe mental handicap due to neonatal meningitis. The coded underlying cause was 3229 (meningitis, unspecified), but we are advised that it should have been 326 (late effects of intracranial abscess or pyogenic infection).

\section{MENTAL SUBNORMALITY AND EPILEPSY}

Mental subnormality or retardation featured in $15(21 \%)$ of the death certificates, and in five of these cases there was no mention of cerebral palsy or another cerebral condition. Epilepsy was mentioned in 14 cases (19\%), including three in which status epilepticus was given under section la.

OTHER CERTIFIED CAUSES OF DEATH

In 57 cases $(78 \%)$ a respiratory (or cardiorespiratory) cause of death appeared on the death certificate, the commonest being bronchopneumonia ( 29 cases). In 20 cases ( $28 \%)$ the coded
Table 3 Cases with respiratory underlying cause of death

\begin{tabular}{llc}
\hline $\begin{array}{l}\text { ICD } \\
\text { code }\end{array}$ & Condition & $\begin{array}{c}\text { No of } \\
\text { cases }\end{array}$ \\
\hline 4660 & Acute bronchitis & 1 \\
4661 & Acute bronchiolitis & 1 \\
4809 & Viral pneumonia-unspecified & 1 \\
$481-$ & Pneumococcal pneumonia & 1 \\
4823 & Pneumonia due to streptococcus & 1 \\
$485-$ & Bronchopneumonia, organism unspecified & 11 \\
$486-$ & Pneumonia, organism unspecified & 2 \\
4919 & Chronic bronchitis-unspecified & 1 \\
$496-$ & Chronic airways obstruction & 1 \\
\hline Total & & 20 \\
\hline
\end{tabular}

underlying cause of death was respiratory, as shown in table 3 .

Reye's syndrome, Stevens-Johnson syndrome, chronic renal failure due to renal tubular acidosis, acute lymphoblastic leukaemia, chicken pox, measles, and pertussis were mentioned in one case each.

In some cases, the information provided on the death certificate appears to conflict with data obtained from other sources. In one case, a 1 year old child said by the attendant clinician to be suffering from hypotonic cerebral palsy, the cause of death 'certified after postmortem without inquest' was given as inhalation of vomit in association with neuromuscular disease (coded 3589: myoneural disorders-unspecified). However, from another source we were told that at postmortem examination the doctor found 'no histological evidence of muscle disease'. One must assume that the results of the histological examination were not available at the time of certification.

\section{POSTMORTEM EXAMINATIONS}

In 23 of the 73 cases (32\%) it was apparent from the copy of the death certificate supplied to us that a postmortem examination had taken place. This was usually because after the name of the certifier appeared the phrase 'after postmortem without inquest'. In one case (396), an accidental death, an inquest had taken place, but the death certificate was not particularly informative. In most cases the box containing the information about whether or not a postmortem examination had been performed had been obscured before the copy was sent to us, so we are not able to be certain that the remaining 49 cases had been certified without necropsy.

In eight (35\%) of the 23 cases known to have had a postmortem examination the underlying cause of death was given as infantile cerebral palsy (343-), and there was a mention of some form of cerebral palsy in four additional cases, hence cerebral palsy appeared on $12(52 \%)$ of certificates in this group. This contrasts with the 49 cases not known to have had a postmortem examination: only eight $(16 \%)$ had the underlying cause coded as 343-, but a total of 33 $(67 \%)$ had a mention of cerebral palsy on the death certificate.

In other respects also, the death certificates issued after postmortem examination are rather less informative than those where a postmortem examination is not mentioned. Particularly disappointing is the fact that in four cases a single 
respiratory cause of death is given with no mention of any other condition. The sole certified causes and approximate age at death of these cases are as follows: lobar pneumonia (14 years), bronchopneumonia (12 years), viral pneumonitis ( 8 years), and acute bronchiolitis (14 months). We have no clinical data on the 8 year old child, owing to follow up difficulties caused by his mother's remarriage, but the other three cases are known to have been both mentally and physically handicapped.

\section{Discussion}

It is the inability to obtain from published data either an estimate of the mortality associated with cerebral palsy, or a true picture of the causes of death across the whole range of affected individuals, which highlights the need for an examination of deaths from population based studies.

The under-representation of chronic 'nonfatal' diseases in mortality statistics is well recognised, ${ }^{12}$ and many of the reasons given are relevant to cerebral palsy. The balance might be redressed in part by a change to multiple cause coding, as discussed by Israel et al who comment ${ }^{5}$ : 'Although the underlying cause of death is conceptually easy to understand and is a well-accepted measure of mortality, often it does not convey the complexity of the reported medical conditions at the time of death. Because most deaths are the result of more than one disease entity, a single underlying cause excludes much useful information on intervening, contributory, and even concurrent conditions'.

The practitioners who complete the death certificates, however, may be unaware of the effect that apparently trivial differences in their mode of expression may have on the categorisation of underlying cause. This problem is discussed by Leadbetter, who concludes that death certificates are completed imprecisely or inaccurately 'because of ignorance of, or failure to apply, the principles of death certification and not because relevant information is lacking. ${ }^{6}$

On 28 death certificates (38\%) there was no mention of any form of cerebral palsy or cerebral birth anoxia, and hence even multiple cause coding would not allow these cases to be ascertained by means of death certificate data. Cerebral palsy is more likely to be mentioned on the death certificate if the child dies in the first few years of life; it is mentioned in less than half the cases dying aged 10 years or more. Most of the children in the study $(90 \%)$ are still alive, and now aged between 10 and 20 years. It remains to be seen if the proportion of death certificates containing a mention of cerebral palsy continues to decline with age.

Underlying cause coding using ICD code 343- (infantile cerebral palsy) would identify only $22 \%$ of cases. One could improve the yield by searching using a greater variety of codes including ICD code 344- (other paralytic syndromes), which was unfortunately used for $7 \%$ of the cases where some form of cerebral palsy was mentioned. If cases coded under this and several other central nervous system categories (microcephaly, meningitis, encephalitis, and cerebral degeneration) had been reviewed manually it would have been possible to pick up nine of the cases not coded 343- but with some sort of cerebral palsy mentioned on the death certificate. This would predict a yield of 25 cases (35\%) using underlying cause coding enhanced by manual review, which is hardly encouraging.

The fact that in $78 \%$ of cases a respiratory (or cardiorespiratory) cause of death was mentioned on the death certificate will come as no surprise to those who are in day to day contact with the severely affected individuals who account for most of the 73 documented deaths. However, the number of cases in which a respiratory illness is coded as the underlying cause of death must be of some concern. While the very young and the very old may succumb to respiratory infections, deaths from such causes in adolescence are relatively uncommon, and the fact that certificates are considered adequate without additional information is surprising.

In January 1984 there was a significant change in the guidance to OPCS coders in the use of World Health Organisation rule 3. ${ }^{7}$ This was in order to prevent certain 'terminal events' (for example, bronchopneumonia, pneumonia, or cardiac arrest) recorded as the only cause of death in part I of the death certificate being coded as the 'underlying cause of death' if the presence of a major disease was recorded in part II. This is a logical way of preventing underrecording, especially of chronic conditions which raise the relative risk of death but which clinicians may be reluctant to cite as 'the' cause of death. However, this change will not achieve its desired effect if the only cause of death appearing on the death certificate is a 'terminal event' such as bronchopneumonia.

It is discouraging to find that this is more likely to happen in cases where the death certificate is stated to have been completed after a postmortem examination. It appears that those responsible for assigning a cause in some postmortem cases are content to limit the expression of their findings to a 'terminal event', even in a few cases giving a detailed description of the nature and extent of the respiratory involvement while neglecting to record the frailty or distortion of the rest of the body associated with many years of immobility, which probably rendered the individual susceptible to a respiratory death. We would not wish to undervalue the use of a postmortem examination to shed light on conditions which had not been elucidated during life. ${ }^{8}$ However, if the pathologist seeks only to demonstrate the presence of bronchopneumonia, or omits relevant necropsy findings, the cause of death given may be more misleading than an informed guess from the attendant clinician.

The consequence of such inadequacy of information is that the number of deaths from respiratory causes in children and adolescents is being inflated by deaths that should be attributed to other causes; the corollary is that the number of deaths from conditions that cause major physical and/or mental handicap is likely to be an underestimate. Duley demonstrated, in a study of 590 stillbirths and neonatal deaths, that the 
presence of congenital malformations was underestimated in death certificates completed without the benefit of necropsy information. ${ }^{9}$ Valuable data from necropsy on congenital malformations, in particular those in the brain which cause some cases of cerebral palsy, may be failing 'to see the light of day' because of the preoccupation with terminal events, particularly in coroners' cases.

Even if the quality of death certificate data were improved, the information obtained would often be insufficient to provide an adequate description of the cause of death, because of the interaction of numerous antecedents before the terminal event. The collection of more detailed information about the period before death poses serious problems, however, even for a population based study. Our experience in the South East Thames region has confirmed that it is difficult to keep track of affected individuals. In addition to normal population mobility, there are transfers away from the notifying paediatrician because individuals become too old to attend a paediatric clinic, or associated with the need for residential or other care. Even paediatric departments with above average record keeping systems have found it surprisingly difficult to inform us of the whereabouts of cases now followed up elsewhere. Family practitioner committees are only able to help with those registered with a general practitioner. Moreover, given that most of the affected children are surviving to adulthood, there are ethical considerations regarding their right to be consulted about being 'followed up': their parents may have consented to the release of medical information and their inclusion upon a register 10 years ago, but a young adult is entitled to take a different view if he or she wishes.

Improvements in quality of information during life, and after death, would lead to benefits for those suffering from a wide range of conditions. It would also prevent misleading conclusions being drawn from inadequate national statistics. It is time for greater effort and, where necessary, finance, to be directed towards strengthening the weak points in the system. The 10th revision of the International Classification of Diseases with new coding rules and recommendations, scheduled to come into operation in 1993, may be regarded as an advance, but will only work if the aims and intentions are fully communicated to all those involved in the certification process. Meanwhile it is important to emphasise the distinction between 'certified' cause of death and 'the' cause, or more often causes, of death, in children and adults suffering from chronic conditions including cerebral palsy.

The authors gratefully acknowledge the cooperation of clinicians and administrative staff in South East Thames region, the provision of survival and death certificate data by the Office of Population Censuses and Surveys and the National Health Service Central Register, and financial assistance from the Spastics Society.

1 Tokuhata G, Miller W, Digon E, Hartman T. Diabetes mellitus: an underestimated public health problem. $f$ Chronic Dis 1975;28:23-35.

2 Ingemar B, Lindahl B, Allander E. Problems in the classification of death diagnoses affecting the reliability of mortality
statistics for rheumatoid arthritis. $\mathcal{F}$ Chronic Dis 1985;38: 409-18.

3 Evans P, Elliott M, Alberman E, Evans S. Prevalence and disabilities in 4 to 8 year olds with cerebral palsy. Arch Dis Child 1985;60:940-5.

4 Evans PM, Evans SJW, Alberman E. Cerebral palsy: why we must plan for survival. Arch Dis Child 1990;65:1329-33.

5 Israel R, Rosenberg H, Curtin L. Analytical potential for multiple cause-of-death data. Am $\mathcal{J}$ Epidemiol 1986;124: 161-79.

6 Leadbetter S. Semantics of death certification. $f R$ Coll Physicians Lond 1986;20:129-32.

7 Office of Population, Censuses and Surveys. Mortality statistics-England and Wales 1984. London: HMSO, 1986. (OPCS Series DH1; 16: vii.)

8 Kircher T, Nelson J, Burdo H. The autopsy as a measure of accuracy of the death certificate. N Engl 7 Med 1985;313: 1263-9.

9 Duley L. A validation of underlying cause of death, as recorded by clinicians on stillbirth and neonatal death certificates. Br $\mathcal{F}$ Obstet Gynaecol 1986;93:1233-5. 